\title{
Expression of oncogenic microRNA-21 in neurospheres and attached cells of a glioblastoma cell line increased after treatment with temozolomide and ionizing radiation
}

\author{
A.R. Rodrigues ${ }^{1}$, F.S.L. Neto ${ }^{1}$, L.G. Lourenço ${ }^{1}$, F.A. Trevisan ${ }^{1}$, \\ M. L.A. Cirino ${ }^{1}$, B. Nery ${ }^{1}$, F.M. Peria ${ }^{2}$, G. Pereira-da-Silva ${ }^{3}$, \\ M.F.G.S. Tazima ${ }^{1}$, L.F. Tirapelli ${ }^{1}$, D.G. Tiezzi ${ }^{4}$, C.G. Carlotti Junior ${ }^{1}$ \\ and D.P.C. Tirapelli ${ }^{1}$ \\ ${ }^{1}$ Departamento de Cirurgia e Anatomia , Faculdade de Medicina de Ribeirão \\ Preto, Universidade de São Paulo, Ribeirão Preto, SP, Brasil \\ ${ }^{2}$ Departamento de Medicina Interna, Faculdade de Medicina de Ribeirão \\ Preto, Universidade de São Paulo, Ribeirão Preto, SP, Brasil \\ ${ }^{3}$ Departamento de Enfermagem Materno-infantil e Saúde Pública, Faculdade \\ de Enfermagem de Ribeirão Preto, Universidade de São Paulo, Ribeirão \\ Preto, SP, Brasil \\ ${ }^{4}$ Departamento de Ginecologia e Obstetrícia, Faculdade de Medicina de \\ Ribeirão Preto, Universidade de São Paulo, Ribeirão Preto, SP, Brasil \\ Corresponding author: D.P.C. Tirapelli \\ E-mail: lab.biomol.cirurgia@fmrp.usp.br
}

Genet. Mol. Res. 18 (2): gmr18095

Received July 31, 2018

Accepted February 19, 2019

Published May 28, 2019

DOI http://dx.doi.org/10.4238/gmr18095

\begin{abstract}
Glioblastomas are the most common primary malignant brain tumors, and despite current advances in therapy, they are still extremely resistant to treatment. The tumorigenic potential of glioblastomas is due to a subpopulation of neoplastic cells, called cancer stem cells (CSCs), which in culture form a suspension cluster called neurospheres. Their properties include tumorigenesis, chemoresistance, and radioresistance. Several miRNAs exhibit altered expression levels during gliomagenesis; thus they constitute one of the key mechanisms for CSC regulation. We evaluated whether temozolomide and ionizing radiation modulate the expression of the tumor suppressor microRNAs-15,-16 and of the
\end{abstract}


oncogenic miR-21 in neurospheres and attached cells in a glioblastoma cell line culture (U343-MG). The methods included staining with Trypan blue to verify cell viability and real time PCR to quantify the expression of microRNAs after exposure to treatments. We observed that miR-16 was more highly expressed in neurospheres than in attached cells $48 \mathrm{~h}$ after treatment with temozolomide, and miR-21 was highly expressed in attached cells compared to neurospheres treated with temozolomide at time $0 \mathrm{~h}(30 \mathrm{~min}$ after treatment); at $48 \mathrm{~h}$ this microRNA was highly expressed in neurospheres treated with temozolomide in association with ionizing radiation. We concluded that the microRNAs were differentially expressed when comparing the different cell types and treatment modalities. The higher expression of miR-21 in neurospheres at time $48 \mathrm{~h}$ may suggest a pathway of CSC radioresistance and chemoresistance, with further rapid tumor growth and recurrence or resistance to other treatment modalities.

Key words: Glioblastoma; Neurospheres; MicroRNAs; Temozolomide; Ionizing Radiation; miR-21

\section{INTRODUCTION}

Primary tumors of the central nervous system (CNS) are a heterogeneous group of benign and malignant tumors amongst which tumors of glial cells, called gliomas, are the most common in adults. Glioblastoma multiform (GBM), grade IV according to the World Health Organization, is the most common primary malignant tumor of the central nervous system and results in a high mortality rate (Louis et al., 2007; Clarke et al., 2010; Louis et al., 2016). Despite aggressive treatments, including surgical resection, radiotherapy and chemotherapy, the median survival time of patients with GBM is around 14.6 months (Stupp et al., 2016). Due to its highly invasive pattern, total resection of the primary tumor mass is not possible, and some tumor-infiltrating cells remain, leading to local disease progression and rarely to metastasis (Wainwright et al., 2012).

Despite many advances in therapeutic approaches, current anti-cancer therapies often fail because they would not be effective against a subpopulation of tumor cells called cancer stem cells (CSCs), which have a greater capacity to repair DNA damage upon exposure to cellular stress and therefore are more resistant to chemo- and radiation therapies (Singh et al., 2003; Bao et al., 2006; Liu et al., 2006).

It has been previously shown that normal neural stem cells formed from adult mice striatum cells, when cultured in serum-free conditions with epidermal growth factor and fibroblast growth factor, do not adhere and are able to divide and differentiate into neurons and astrocytes (Reynolds et al., 1992). Based on a neurosphere assay, several research groups have identified a small number of cells with clonogenic potential and with stem cell characteristics (Quesenberry et al., 1999; Singh et al., 2006). Neurosphere cells show extensive self-renewal capacity, and the ability to differentiate into the main types of brain cells (neurons, astrocytes and oligodendrocytes) (Jordan et al., 2006). 
Evidences suggest that microRNAs play an essential role in the regulatory mechanisms of cancer stem cells (González-Gómez et al., 2011). MiRNAs are small noncoding RNAs (ncRNAs), consisting of 19-25 nucleotides, that act as post-transcriptional important regulators of gene expression through degradation or translational repression of targeted messenger RNAs (mRNA) (Cowland et al., 2007; Guo et al., 2010). MiRNAs have been implicated in processes such as cell differentiation, proliferation, apoptosis, and cell metabolism and thus deregulation of miRNA expression can lead to various diseases, including cancer (Kulshreshtha et al., 2007). MicroRNAs are important in maintaining the balance between oncogenes and tumor suppressor genes (Amaral et al., 2010). Some miRNAs promote cell proliferation and inhibition of apoptosis, whereas others lead to decreased survival and cell proliferation. These two types of microRNAs are called oncogenic microRNAs and tumor suppressor microRNAs, respectively (Gartel et al., 2008).

Several microRNAs that are overexpressed in glioblastoma are known (Moller et al., 2013). Studies have shown that the inhibition of these microRNAs leads to a decreased growth rate of tumor cells, invasion and angiogenesis (Zhou et al., 2010; Lin et al., 2012), suggesting that these molecules have a significant therapeutic potential. Knowledge of the correlation between microRNA expression levels and glioblastoma pathogenesis has led to the identification of specific microRNAs in cancer stem cells that have potential therapeutic applicability (Halle et al., 2016). We analyzed whether temozolomide and ionizing radiation, isolated or combined, modulates the expression of both tumor suppressor microRNAs (miR-15 and miR-16) and the oncogenic microRNA (miR-21) in neurospheres and attached cells from a glioblastoma cell line.

\section{MATERIAL AND METHODS}

\section{Cell culture}

U343MG - a cell line originally purchased from the American Type Culture Collection (ATCC) (Rockville, MD, USA) was kindly provided by Prof. James T. Rutka (The Arthur and Sonia Labatt Brain Tumour Research Centre, Canada); it was divided into suspension and adhesion culture, and grown in $25-\mathrm{cm}^{2}$ flasks $\left(\mathrm{TPP}^{\circledR}\right)$ with an ideal medium for cultivating brain cancer stem cells, composed of Dulbecco's Modified Eagle's Medium/F12 medium (DMEM/F12, Gibco $\left.{ }^{\circledR}\right)$, EGF $\left(20 \mathrm{ng} / \mathrm{mL}\right.$, Gibco $\left.^{\circledR}\right)$ and bFGF (20 $\left.\mathrm{ng} / \mathrm{mL}, \mathrm{Gibco}^{\circledR}\right)$ for the cells in suspension; Dulbecco's Modified Eagle's Medium/F12 medium (DMEM/F12, Gibco ${ }^{\circledR}$ ) and 10\% fetal bovine serum (FBS), for the cells to grow in attached monolayers on the flasks. All the cells were kept incubated at $37^{\circ} \mathrm{C}$ and $5 \% \mathrm{CO}_{2}$ until they reached the cell confluence necessary $\left(10^{5}\right.$ cells per culture flask).

\section{Experimental subgroups}

For the division into four experimental subgroups, we used 12 well plates. One thousand cells were distributed to each subgroup, and all experiments were performed in triplicate.

- Control group: cells were collected without any treatment. 
- TMZ group: Temozolomide [340 $\mu \mathrm{M}$ ] (TEMODAL®, Schering-Plough, Turku, Finland) was dissolved in sterile water and filtered, and the drug remained in culture for 24 $\mathrm{h}$. Cells were then washed with medium and replaced in culture for another $48 \mathrm{~h}$.

- IR group: $\left({ }^{60} \mathrm{Co}\right.$ source, dose rate of $2.0 \mathrm{~Gy} / \mathrm{min}$, Unit Gammatron S-80, Siemens, $1.25 \mathrm{MeV}$, HC-FMRP/USP), with final dose of $14 \mathrm{~Gy}$. The radiation dose of 14 Gy was chosen on the basis of previous clonogenic survival experiments made by our group.

- TMZ+IR group: treatment with temozolomide following IR. This treatment sequence was based on the treatment protocol of patients with glioblastoma (4).

The cells of subgroups were collected and analyzed at two different times: the first, about $30 \mathrm{~min}$ after the treatments (time named $0 \mathrm{~h}$ ), and another $48 \mathrm{~h}$ after the treatments (time named 48h).

\section{Cell viability}

To assess cell viability, we used the exclusion test with Trypan Blue, a dye marker for dead cells. We gathered $50 \mu \mathrm{L}$ of cells in $50 \mu \mathrm{L}$ of Trypan Blue $(0.4 \%)$. Cells were counted in a Neubauer counting chamber, wherein translucent cells were considered viable, and cells with blue staining were considered dead.

\section{RNA isolation and real-time PCR}

Total RNA was extracted from cells of all experimental subgroups (30 min and $48 \mathrm{~h}$ after temozolomide and ionizing radiation) using the Trizol reagent (Invitrogen, Carlsbad, CA, USA) according to the manufacturer's instructions. In order to verify the integrity of the RNA, each sample was subjected to electrophoresis on agarose gel 1\% RNA and using a spectrophotometer we determine the RNA concentration and purity (206/280 ratio) in the samples.

To prepare the PCR, reverse transcription of RNA samples was performed using the High-Capacity cDNA kit (Applied Biosystems, USA).

\section{Real time PCR}

The cDNA was amplified with quantitative Real Time PCR (q-PCR) using TaqMan Master Mix (Applied Biosystems) for the reaction of microRNAs. RNU24 and RNU48 were used as endogenous controls for the reaction of the microRNAs. All reactions were carried out in duplicate and analyzed with the 7500 Sequence Detection System apparatus (Applied Biosystems). The data were analyzed using the ABI-7500 SDS software.

\section{Statistical Analysis}

Data concerning the microRNAs in all groups were analyzed statistically with a Two-Way ANOVA test followed by the Bonferroni post-test using the GraphPad Prism software (GraphPad Software, San Diego, CA, USA). The level of significance was set at $\mathrm{P}$ $<0.05$ for two-tailed tests. 


\section{RESULTS}

\section{Cell viability}

Cell viability was analyzed in neurospheres and attached cells treated with temozolomide and/or ionizing radiation and collected immediately (30 min after treatments, time 0 ) and $48 \mathrm{~h}$ after treatments.

We found significant differences between the rates of cell viability of the samples collected immediately and $48 \mathrm{~h}$ after exposure to treatments. Treatment with temozolomide or ionizing radiation, or with both combined, significantly decreased $(\mathrm{P}<0.001)$ the viability of both neurospheres (Figure 1) and attached cells (Figure 2).

\section{Neurospheres}

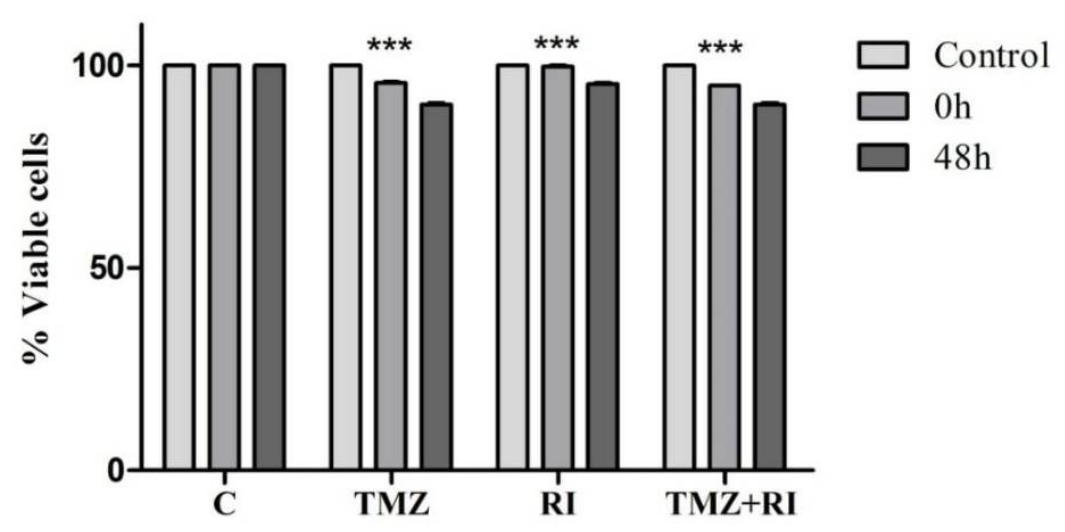

Figure 1: Cell viability of neurospheres of control and treated groups in different periods. There were significant differences among the variables of treatment and time $(\mathrm{P}<0,001$, Bonferroni post-test).

\section{Attached cells}

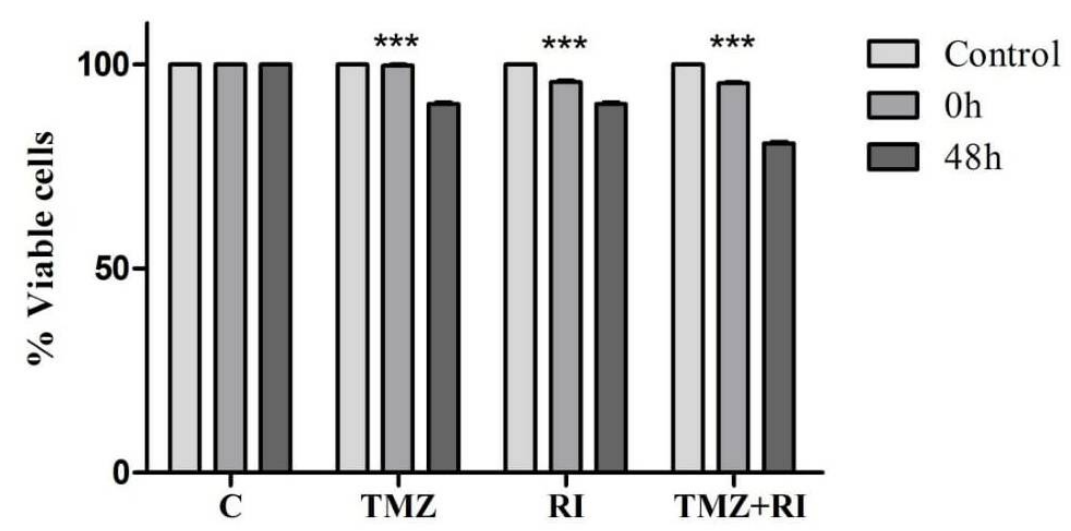

Figure 2: Cell viability of attached cells of control and treated groups in different periods. There were significant differences among the variables of treatment and time ( $\mathrm{P}<0,001$, Bonferroni post-test). 


\section{Expression profile of microRNAs}

Using the $2^{-\Delta \Delta \mathrm{Ct}}$ method, we analyzed the post-transcriptional expression of miR-21 (antiapoptotic), miR-15 and miR-16 (tumor suppressors) by real-time PCR. We observed that, at time $0 \mathrm{~h}$, the oncogene miR-21 was highly expressed in attached cells compared to neurospheres treated with temozolomide (Figure 3), but at time $48 \mathrm{~h}$ this microRNA was highly expressed in neurospheres treated with temozolomide and ionizing radiation $(\mathrm{P}<0.01)$.
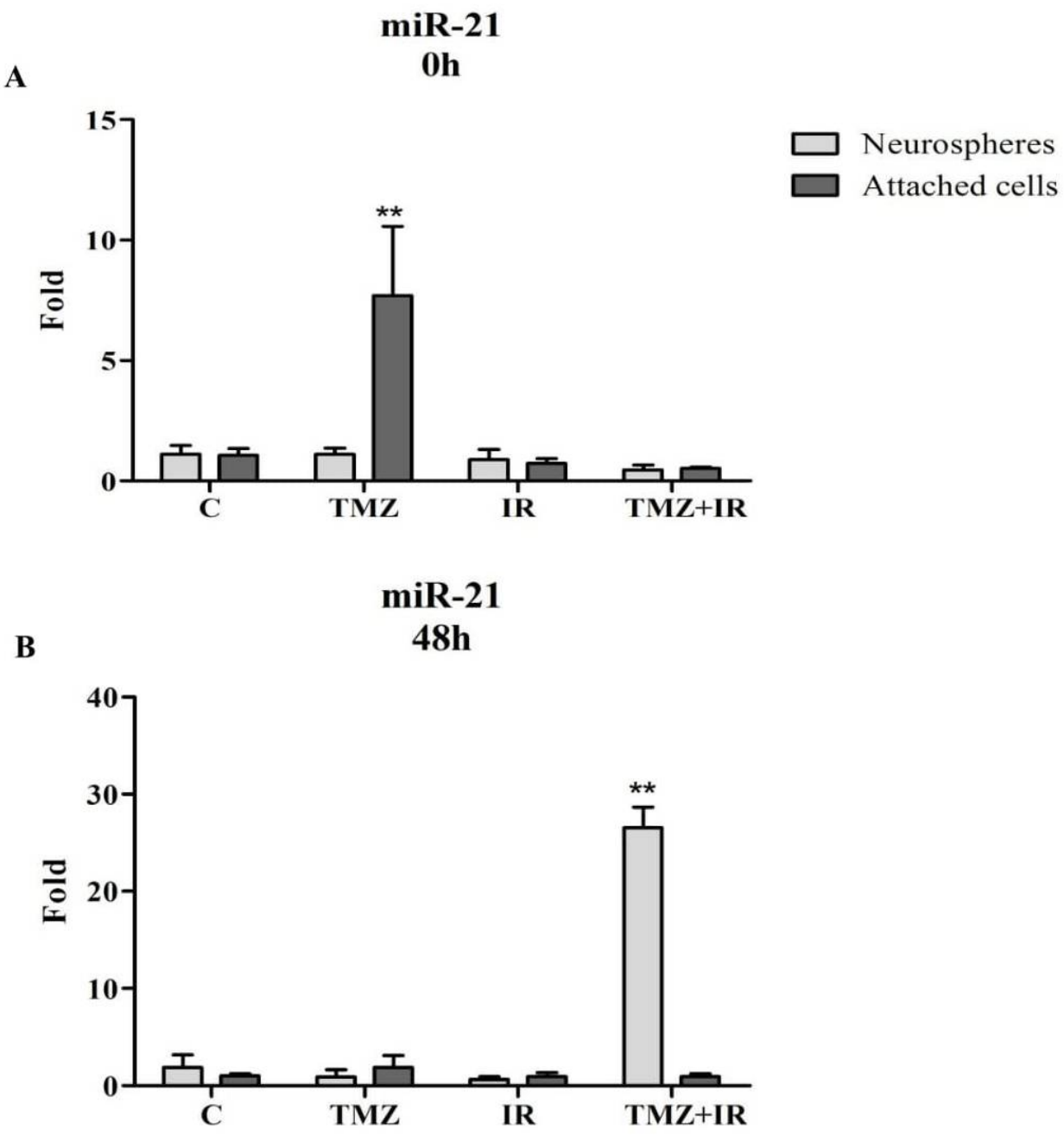

Figure 3: Expression of microRNA-21 over treatment modalities (TMZ, RI, TMZ + RI) at times $0 \mathrm{~h}$ and 48h. At $0 \mathrm{~h}$, the microRNA-2 1 expression was significantly increased $(\mathrm{P}<0.01$, Bonferroni post-test $)$ in attached cells compared to neurospheres in the group treated with TMZ. At 48h, the microRNA-21 expression was significantly increased $(\mathrm{P}<0.01$, Bonferroni post-test $)$ in neurospheres compared to attached cells in the group treated with TMZ+IR. 
The tumor suppressor miR-16 was highly expressed in neurospheres treated with ionizing radiation $(\mathrm{P}<0.01$ ), while miR-15 expression did not differ over time (Figure 4 and 5).

A

miR-15

Oh

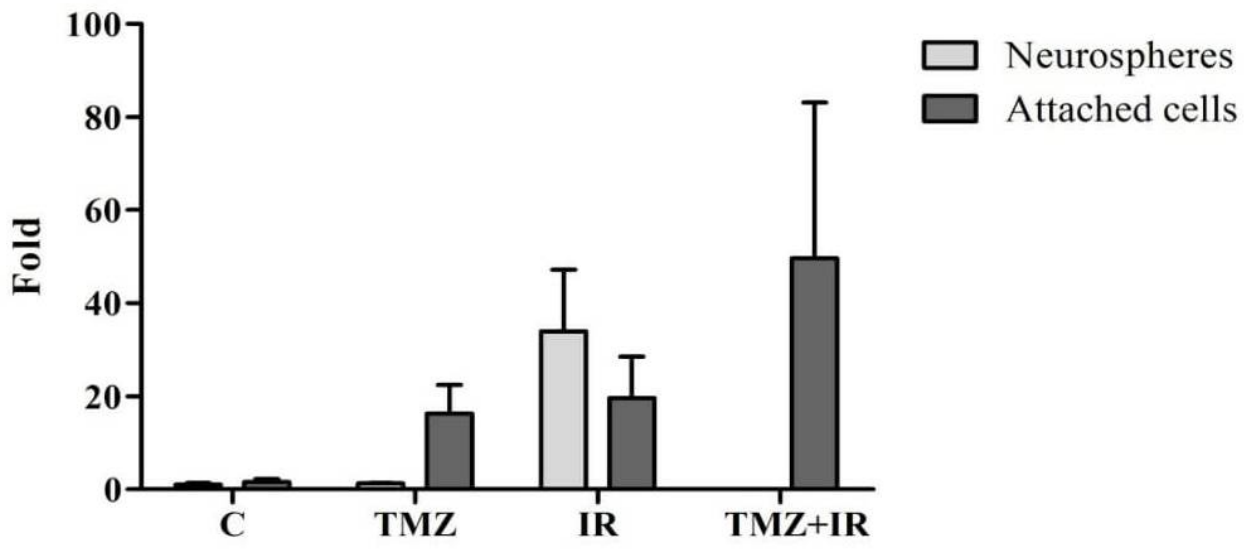

B

miR-15

$48 \mathrm{~h}$

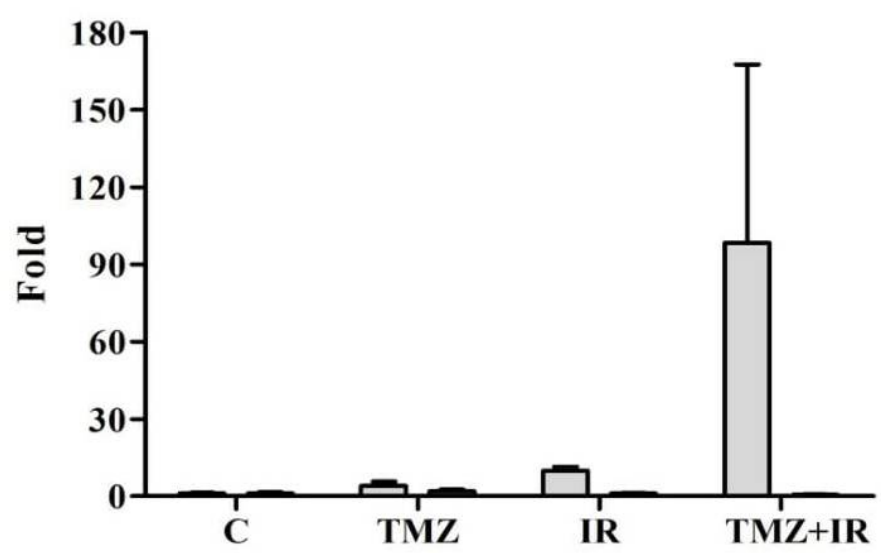

Figure 4: Expression of microRNA-15 over treatment modalities (TMZ, RI, TMZ + RI) at times 0h and 48h. There was no significant difference in the expression of miR-15 ( $\mathrm{P}>0.05$, Bonferroni post-test) between neurospheres and attached cells at both analysis times. 


\section{miR-16}

Oh

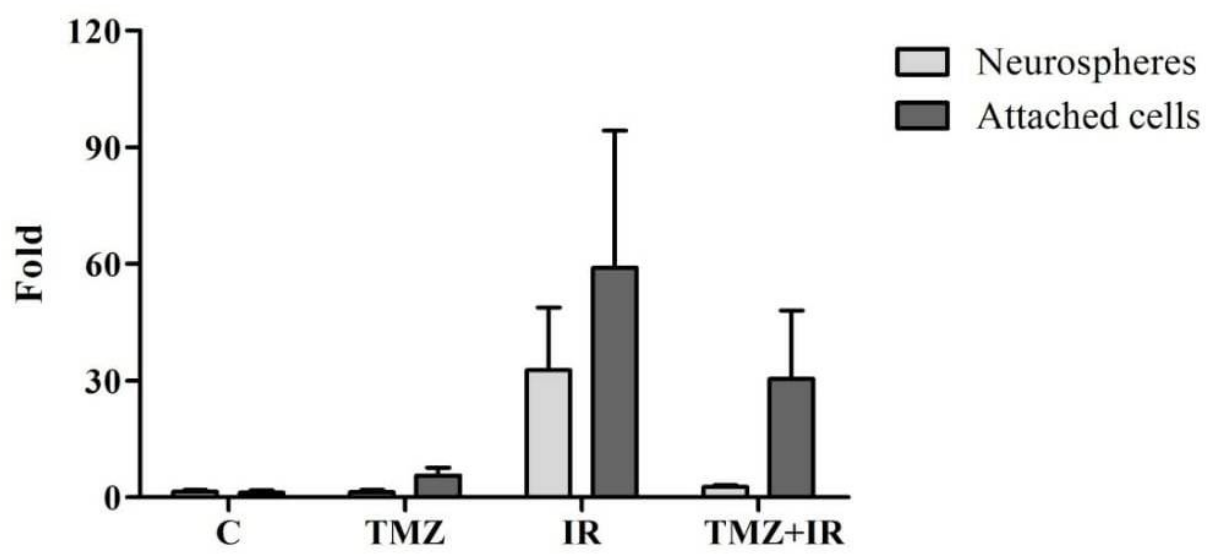

miR-16

$48 \mathrm{~h}$

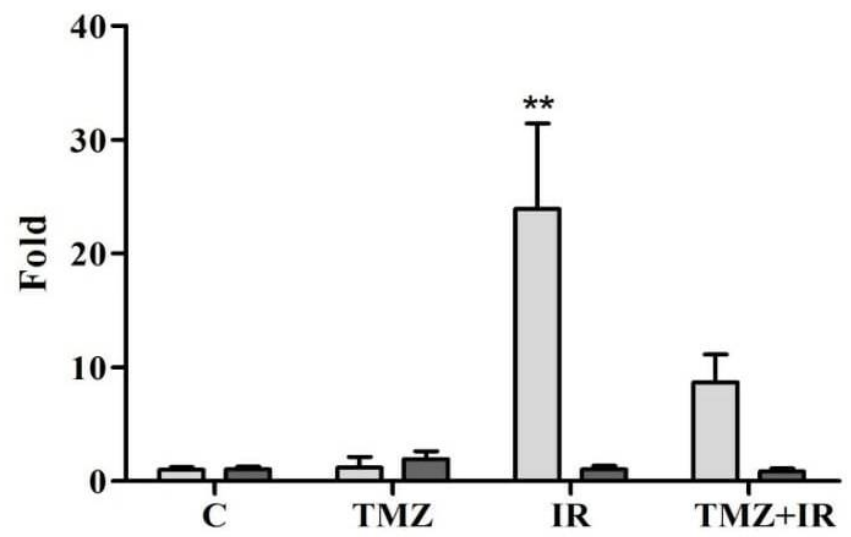

Figure 5: Expression of microRNA-16 overtreatment modalities (TMZ, RI, TMZ + RI) at times $0 \mathrm{~h}$ and $48 \mathrm{~h}$. At time $0 \mathrm{~h}$, there was no significant difference in the expression of miR-16 (P > 0.05, Bonferroni post-test) between neurospheres and attached cells. At time $48 \mathrm{~h}$, microRNA-16 expression was significantly increased $(\mathrm{P}<0.01$, Bonferroni post-test) in neurospheres compared to attached cells in the group treated with IR.

\section{DISCUSSION}

One of the hypotheses of this study is that temozolomide and ionizing radiation modulate the expression of microRNAs involved in the development of glioblastoma. The selection of microRNA targets was based on previous reports of changes in their expression within tumors of the central nervous system, particularly in glioblastomas. Therefore, we asked whether the differences between the expression of microRNAs miR-21, miR-15 and 
miR-16 in neurospheres that contain cancer stem cells, and in the cells that grow attached to the culture surface - called "non-stem" cells - in the U343 cell line would occur.

Much has been investigated about the involvement of microRNAs in cancer stem cell functions, given the fact that the expression levels of certain microRNAs in stem cells are different from those in other cell types (Ondracek et al., 2017). Molecular therapy based on microRNAs might interfere in the CSCs self-renewal capacity, decrease resistance to treatment, and consequently, hinder tumor recurrence (DeSano et al., 2009; Halle et al., 2016).

The antiapoptotic oncomiR-21 is overexpressed in several tumor types, including glioblastoma, and it has as its main targets: p53, APAF1, PTEN, caspase-3 (Chan et al., 2005; Zhou et al., 2010). In solid tumors, increased expression of microRNA-21 is significantly associated with worse prognosis of high-grade gliomas and breast cancers. In the latter, miR-21 expression is correlated with worse prognosis, including advancement of the clinical stage and lymph node metastasis (Feng, Tsao, 2016). Thus, high expression of miR-21 induces overexpression of proteins essential to the development of many cancers, including leukemias, lung, colon, lymphomas, carcinomas, etc. (Si et al., 2007; Gabriely et al., 2008). Indispensable for cancer stem cells, deregulation of apoptosis pathways is essential for cell survival and self-renewal of tumor cells (Reya et al., 2001) and blood vessel morphogenesis (Gabriely et al., 2008).

A previous study with the lineage of human glioblastoma U251 has shown that miR-21 inhibition decreases radiation resistance and increases the rate of apoptosis in cells, confirming the oncogenic role of miR-21 (Chistiakov et al., 2012). In another study with primary glioblastoma cells, miR-21 was overexpressed following the first hours of irradiation, but decreased after $24 \mathrm{~h}$ (Chaudhry et al., 2010). We found that microRNA-21 expression in attached cells increased after treatment with TMZ, but then decreased after 48 $\mathrm{h}$ of treatment. Also, the microRNA-21 had a higher expression level in neurospheres when compared to attached cells after treatment with temozolomide and ionizing radiation. According to Singh et al. (2008), the decrease in miR-21 expression in attached cell population after $48 \mathrm{~h}$ of treatment with temozolomide supports the induction of apoptosis, while increased expression of this miRNA in the neurospheres possibly contributes to preventing apoptosis. Based on these findings, we suggest that miR-21 expression is related to treatment resistance, specifically in the population of neurospheres, regardless of time. An association of microRNA-21 with resistance to temozolomide in the glioblastoma line U251 has been previously suggested in a study in which TMZ failed to induce apoptosis in cancer stem cells (Zhang et al., 2012). On the other hand, TMZ has been shown to inhibit cell proliferation and to induce apoptosis in non-stem glioma cells (Yang et al., 2006). These results reinforce the crucial role of CSCs in the resistance to current therapies, given the fact that these cells have a greater capacity to repair DNA damage than non-stem cells.

It has been suggested that gliomas respond to treatment according to the modulation of various miRNAs and that the differences in their modulation may be the basis for the sensitivity of cells to treatment (Chaudhry et al., 2010). As shown in our study, U343-MG cells are highly resistant to treatment with ionizing radiation and temozolomide; the expression levels of the microRNAs miR-21 and miR-15 increased after $24 \mathrm{~h}$ of treatment. However, miR-21 expression decreased after $48 \mathrm{~h}$, whereas miR-15 expression remained increased (Trevisan, 2011). In M059K and M059J glioma cell lines, the expression of miR15 and miR-16 microRNAs have been shown to increase after $8 \mathrm{~h}$ of treatment with ionizing 
radiation, but then decreased shortly after; yet, miR-16 expression increased $12 \mathrm{~h}$ after treatment, and, similarly decreased after this period (Chaudhry et al., 2010).

In neurospheres, we showed that microRNA-16 expression significantly increased after $48 \mathrm{~h}$ of treatment with ionizing radiation, whereas microRNA-15 expression was similar in attached cells and neurospheres. In breast cancer, it has been shown that the higher the miR-15 and miR-16 expression, the lower the formation of spheres as well as the expression of other markers of breast cancer stem cells, such as CD44 (Polytarchou et al., 2012).

Treatment with TMZ has been shown to reduce the formation of spheres of samples of primary cultures of glioblastoma in time and dose-dependent conditions (Beier et al., 2011). In our study, we observed a greater relationship between neurospheres and the standard treatment for glioblastoma, since we found increased expression of an oncomiR associated with increased resistance to treatment.

\section{CONCLUSIONS}

Understanding the expression of microRNAs in neurospheres and attached cells of glioblastoma cell line treated with temozolomide and ionizing radiation is of great interest since alternative blockage pathways of tumor progression and relapses are of paramount importance to reduce morbidity and mortality of such a malignant tumor. In our study, the microRNAs were differentially expressed when comparing the different cell types, treatment modalities and post-exposure time. The higher expression of the oncogenic miR21 in neurospheres at time $48 \mathrm{~h}$ may suggest a pathway of CSC radioresistance and chemoresistence, with further rapid tumor growth and recurrence or resistance to other treatment modalities. The role of higher expression of MiR-16 (tumor suppressor microRNA) in neurospheres than in attached cells $48 \mathrm{~h}$ after treatment with temozolomide is yet to be understood.

In conclusion, although therapy of malignant gliomas based on microRNAs remains under investigation, it provides great potential for future applications and clinical intervention, in association with existing therapies. The development of inhibitors of some types of microRNAs, such as microRNA-21, could increase the efficiency of the treatment of gliomas, especially those associated with cancer stem cells.

\section{ACKNOWLEDGMENTS}

ARR was supported by a scholarship from the CAPES (Coordenação de Aperfeiçoamento de Pessoal de Nível Superior).

\section{REFERENCES}

Amaral BAD, Nonaka CFW, Freitas RDA, Souza LBD, et al. (2010). MicroRNAs - Biogênese, funções e seu papel potencial na carcinogênese oral. Odontol. clín-cient. 9: 105-109.

Bao S, Wu Q, McLendon RE, Hao Y, et al. (2006). Glioma stem cells promote radioresistance by preferential activation of the DNA damage response. Nature. 444: 756-760.

Beier D, Schulz JB and Beier CP (2011). Chemoresistance of glioblastoma cancer stem cells-much more complex than expected. Mol. Cancer. 10: 128.

Chan JA, Krichevsky AM and Kosik KS (2005). MicroRNA-21 is an antiapoptotic factor in human glioblastoma cells. Cancer Res. 65: 6029-6033. 
Chaudhry MA, Sachdeva H and Omaruddin RA (2010). Radiation-induced micro-RNA modulation in glioblastoma cells differing in DNA-repair pathways. DNA. Cell Biol. 29: 553-561.

Chistiakov DA and Chekhonin VP (2012). Contribution of microRNAs to radio- and chemoresistance of brain tumors and their therapeutic potential. Eur. J. Pharmacol. 684: 8-18.

Clarke J, Butowski N and Chang S (2010). Recent advances in therapy for glioblastoma. Arch. Neurol. 67: 279-283.

Cowland JB, Hother C and Grønbaek K (2007). MicroRNAs and cancer. APMIS. 115: 1090-1106.

DeSano JT and Xu L (2009). MicroRNA regulation of cancer stem cells and therapeutic implications. AAPS J. 11: 682692.

Feng YH and Tsao CJ (2016). Emerging role of microRNA-21 in cancer. Biomed. Rep. 5: 395-402.

Gabriely G, Wurdinger T, Kesari S, Esau CC, et al. (2008). MicroRNA 21 Promotes Glioma Invasion by Targeting Matrix Metalloproteinase Regulator. Mol. Cell. Biol. 17: 5369-5380.

Gartel AL and Kandel ES (2008). miRNAs: Little known mediators of oncogenesis. Semin. Cancer Biol. 18: 103-110.

González-Gómez P, Sánchez P and Mira H (2011). MicroRNAs as regulators of neural stem cell-related pathways in glioblastoma multiforme. Mol. Neurobiol. 44: 235-249.

Guo H, Ingolia NT, Weissman JS and Bartel DP (2010). Mammalian microRNAs predominantly act to decrease target mRNA levels. Nature. 466: 835-840.

Halle B, Thomassen M, Venkatesan R, Kaimal V, et al. (2016). Shift of microRNA profile upon orthotopic xenografting of glioblastoma spheroid cultures. J. Neurooncol. 128: 395-404.

Jordan CT, Guzman ML and Noble M (2006). Cancer stem cells. N. Engl. J. Med. 355: 1253-1261.

Kulshreshtha R, Ferracin M, Negrini M, Calin GA, et al. (2007). Regulation of microRNA expression: the hypoxic component. Cell Cycle. 6: 1426-1431.

Lin J, Teo S, Lam DH, Jeyaseelan K, et al. (2012). MicroRNA-10b pleiotropically regulates invasion, angiogenicity and apoptosis of tumor cells resembling mesenchymal subtype of glioblastoma multiforme. Cell Death Dis. 3: e398.

Liu G, Yuan X, Zeng Z, Tunici P, et al. (2006) Analysis of gene expression and chemoresistance of CD133+ cancer stem cells in glioblastoma. Mol. Cancer. 5: 67.

Louis DN, Ohgaki H, Wiestler OD, Cavenee WK, et al. (2007). The 2007 WHO classification of tumours of the central nervous system. Acta Neuropathol. 114: 97-109.

Louis DN, Perry A, Reifenberger G, Von Deimling A, et al. (2016). The 2016 World Health Organization Classification of Tumors of the Central Nervous System: a summary. Acta Neuropathol. 131: 803-820.

Møller HG, Rasmussen AP, Andersen HH, Johnsen KB, et al. (2013). A systematic review of microRNA in glioblastoma multiforme: micro-modulators in the mesenchymal mode of migration and invasion. Mol. Neurobiol. 47: 131-144.

Ondracek J, Fadrus P, Sana J, Besse A, et al. (2017). Global MicroRNA Expression Profiling Identifies Unique MicroRNA Pattern of Radioresistant Glioblastoma Cells. Anticancer. Res. 37: 1099-1104.

Polytarchou C, Iliopoulos D and Struhl K (2012). An integrated transcriptional regulatory circuit that reinforces the breast cancer stem cell state. Proc. Natl. Acad. Sci. U S A. 109: 14470-14475.

Quesenberry PJ, Hulspas R, Joly M, Benoit B, et al. (1999). Correlates between hematopoiesis and neuropoiesis: neural stem cells. J. Neurotrauma. 16: 661-666.

Reya T, Morrison SJ, Clarke MF and Weissman IL (2001). Stem cells, cancer, and cancer stem cells. Nature. 414: 10511.

Reynolds BA and Weiss S (1992). Generation of neurons and astrocytes from isolated cells of the adult mammalian central nervous system. Science. 255: 1707-10.

Si ML, Zhu S, Wu H, Lu Z, et al. (2007). miR-21-mediated tumor growth. Oncogene. 26: 2799-2803.

Singh SK, Clarke ID, Terasaki M, Bonn VE, et al. (2003). Identification of a cancer stem cell in human brain tumors. Cancer Res. 63: 5821-5828.

Singh SK, Pal Bhadra M, Girschick HJ and Bhadra U (2008). MicroRNAs--micro in size but macro in function. FEBS J. 275: 4929-4944.

Stupp R, Hegi ME, Gilbert MR and Chakravarti A (2007). Chemoradiotherapy in malignant glioma: standard of care and future directions. J. Clin. Oncol. 25: 4127-4136.

Trevisan FA (2011). MicroRNAs related to apoptosis and MGMT in glioblastoma cell line subjected to treatment with ionizing radiation and temozolomide. University of São Paulo, Brazil.

Wainwright DA, Nigam P, Thaci B, Dey M, et al. (2012). Recent developments on immunotherapy for brain cancer. Expert. Opin Emerg. Drugs. 17: 181-202.

Yang SH, Kim MK, Lee TK, Lee KS, et al. (2006). Temozolomide chemotherapy in patients with recurrent malignant gliomas. J. Korean Med. Sci. 21: 739-744.

Zhang S, Wan Y, Pan T, Gu X, et al. (2012). MicroRNA-21 inhibitor sensitizes human glioblastoma U251 stem cells to chemotherapeutic drug temozolomide. J. Mol. Neurosci. 47: 346-356.

Zhou X, Ren Y, Moore L, Mei M, et al. (2010). Downregulation of miR-21 inhibits EGFR pathway and suppresses the growth of human glioblastoma cells independent of PTEN status. Lab. Invest. 90: 144-155. 